\title{
Leukemia Secondary To Oncology Chemotherapy, CTCAE
}

National Cancer Institute

\section{Source}

National Cancer Institute. Leukemia Secondary To Oncology Chemotherapy, CT CAE. NCI

Thesaurus. Code C143646.

A disorder characterized by leukemia arising as a result of the mutagenic effect of

chemotherapy agents. 